\section{To the Benefit of Both: Academic Librarians Connect with Middle School Teachers through a Digitized History Resources Workshop}

\section{Nancy P. Shires}

A workshop sponsored by the North Carolina Collection at East Carolina University to familiarize middle school teachers with the Eastern Carolina Digital History Exhibits and provide lesson plans for the site revealed (1) the need for teachers and librarians to work more closely together in the design and use of new digital history resources and (2) the benefits of cooperative efforts. Although the K-12 community generally welcomes digital resources, teachers face important challenges, such as redesigning the curriculum. What the teachers had to say, as well as a few other unexpected findings, proved beneficial to the librarians in creating sites. Small workshops were shown to be useful to both teachers and librarians.

\section{Librarians Connect Naturally with Educators}

Academic librarians are actively digitizing their unique historical records, and, like other digitizers, have always recognized the $\mathrm{K}-12$ community as natural and immediate users of their sites. Digitizers

Nancy P. Shires (shiresn@mail.ecu .edu) is Professor in the North Carolina Collection, East Carolina University, Greenville. "know the value of their materials and believe that they will benefit the classroom."1 They see easier and wider access for students and more active involvement with history, for example, as a way to benefit poorer schools as well as richer ones. Academic librarians in public and land-grant institutions may, in fact, have a legal obligation to serve the schools. ${ }^{2}$ These institutions were founded to provide broad educational opportunities to the general population and, in order to receive funding, are required to practice openness, accessibility, and service in their operations.

Larger academic libraries and other larger cultural institutions were the first to offer their unique resources and primary documents on the Internet, but digital-history initiatives and projects no longer reside only with them. Digitizing projects are growing "from a trickle ... to a cascade." ${ }^{3}$

The increase in digitizing, however, does not automatically mean that librarians understand the need or uses for their products in the classroom. In fact, most librarians have only general and informal knowledge of what teachers actually do with their digitized historical sites or whether they know about them or use them at all. About this situation, Cherry writes: "If the caretakers of cultural-heritage materials are serious about serving the $\mathrm{K}-12$ community . . . then they must know their K-12 audience better." 4

There is no doubt that teachers will continue to seek these sites. Some states now mandate the use of primary resources and technology in the classroom, which means that schools must look to acquire these. Digitized resources help teachers meet state requirements without great cost to the schools. Public schools and their media centers or libraries are, of course, greatly limited in resources, funding, and space. A typical mediacenter history collection might consist in the main of biographies and a reference section with historicalbiographical dictionaries and encyclopedias-including specialized ones covering such groups as African American women-for the broad range of historical periods. In addition to these materials, the libraries usually offer access to the Internet and thus to sites with relevant primary documents, often through special lowcost, state-sponsored programs and sometimes through grants. It is into this extension of the school libraries' actual resources that academic-library digital sites fall.

In addition, teachers generally "want students to place a higher value on those (Web sites) that are sponsored by universities, museums, or faculty." 5 They are looking to academic librarians, among others, to develop high-quality, usable, classroom-relevant sites. Although this article describes academic-library sites, it will be useful to other digitizers, such as museums and historical societies, because they, too, potentially serve the $\mathrm{K}-12$ audience.

A look at the education literature and at our own experience with a workshop for teachers supports the idea that, in spite of what is known about the K-12 classroom, librarians involved in digitizing do indeed need to work more closely with practicing classroom teachers. For librarians who are considering ways to integrate their digitized history into the classroom or who are actually planning to work with teachers, these considerations can benefit their efforts.

\section{Digital History in the Classroom}

The $\mathrm{K}-12$ teaching community generally has welcomed digital history sites available on the Internet. Recent issues of such journals as The History Teacher, Theory and Research in Social Education, and Journal of the Association for History and Computing 
reveal the recognition of the value or potential value of digitized history among education scholars and classroom teachers. Online primary sources have been shown, for example, to encourage recursive reading and a better grasp of historical causation. ${ }^{6}$ These sources can be used to increase students' problem-solving skills, critical and complex thinking, and multicultural awareness. The American Historical Association recommends active learning in which students act as historians, comparing and evaluating texts, placing events in context, or revising opinion based on new evidence. A well-organized and accessible collection of online documents allows and encourages students to engage in such real study of history. And students tend to remember better and longer what they find out for themselves than what they are simply told. Lee also points out that "an online document can be made use of through online social networks in ways that non-digital documents cannot be used. This important difference is often overlooked when evaluating the value of digital resources."7

\section{Problems with K-12 Teachers' Use of Digital Sites}

Research in the educational literature indicates that teachers, especially social-studies teachers, need training in the use of new resources on the Web and that "intense small-group workshops for faculty" are needed. ${ }^{8}$ Teachers might also need training in computer use. Most teachers do not enjoy using computers for instruction, and even enthusiastic student teachers lose much of their enthusiasm after the first year. ${ }^{9}$ In his article "Ten Ways to Integrate Technology into Middle School Social Studies," Braun notes the uneven growth of technology in the classroom, and advises teachers to find mentors and attend presentations, workshops, and institutes. ${ }^{10}$

Some reasons for hesitancy in using technology include the lack of enough computers at which students can work individually or in groups, or the difficulty in getting the class to a tightly scheduled computer lab for instruction. It cannot be assumed that students can learn the sites sufficiently on their own or that they have sufficient nonschool access to computers. Even when such access is present, the initial work with a lesson based on a digital site usually occurs in the classroom. Technical support might also be an issue-computers and the Internet must be working reliably. Supervision of the students is needed as they work on the computers, to make sure they are finding and using correct or relevant sources and understanding what they are seeing, at least initially. The teacher, of course, first needs to become thoroughly familiar with the sites and documents being used and to be adept at manipulating them.

Research also indicates that the number of new resources is overwhelming, and that having highquality, relevant sources pointed out to teachers is useful. Teachers ask, "How do I wade through the overwhelming amount of 'information' on the Web to access the remarkable array of historical documents and research now available online?"11 Frequent articles in the educational literature are bibliographies of good sites for teachers to use.

Online sites sponsored by academic libraries and others, besides providing links to other useful sites or bibliographies, frequently offer "added value features," such as grade-specific lesson plans based on the site and particular documents in it. ${ }^{12}$ Workshops provide individual guidance to teachers in use of the technology, the site, the individual documents, and the added value features. More than just describing a good site or sites, workshops help teachers to know the site and its contents and to use these effectively.

\section{The Workshop for Teachers}

The Eastern North Carolina Digital History Exhibits (ENCDHE) (www. lib.ecu.edu/exhibits) at Joyner Library, East Carolina University, went public in September 2001. This was the library's first foray into digital projects. Five categories of historical documents, called exhibits, were presented here at the time of the workshop: East Carolina University Centennial, John Lawson, Tobacco, Steamers, and Wright Brothers. The North Carolina Collection at Joyner Library sought to support eighthgrade social-studies teachers in the state through a workshop that would result in lesson plans to accompany the site and thus make the digitized resources here more useful in classrooms across the state. The East Carolina workshop carried continuing-education credit, which teachers in most states are required to earn in order to renew their teaching certificates. The workshop format was chosen because of teachers' need for formal continuing education, especially in technical areas, and for its intensive educational value.

Two members of the North Carolina Collection, Maury York and Nancy Shires, received a grant from the Rural Education Institute (REI) at East Carolina University to hold a workshop that would: (1) make a small group of teachers in a largely rural region aware of the new digital site, its value, and its use; and (2) result in six lesson plans for each component of the site, so that other teachers could use the resources more readily in their own classrooms. Eighth grade is the year that North Carolina children study the history of their state, so middle-school teachers were targeted. 
At the workshop held June 27, 2003, the teachers worked with the experts or principal investigators responsible for creating the components of the digital exhibits, and they wrote the first of three lesson plans. Two other plans were due that summer. In the fall, one plan was tested in the classroom and all plans were revised and submitted by February 2004 to be mounted on the Web site. Teachers received payment and continuing-education credit both in June and in February. Their names appear on the Web site with the plans they created.

To develop their lesson plans for the ENCDHE site, teachers used a common template developed by Joyner Library reference librarian Joseph Thomas, based on the standard format used in the North Carolina public schools and approved by REI. The template required teachers to cite goals and objectives from the North Carolina Standard Course of Study (NCSCS), and a link to the Standard Course was provided. Plans also clearly state the grade level and subject.

\section{What the Teachers Said}

The nine teachers who participated in the workshop evaluated it before leaving and gave it high marks. They said the experts with whom they worked were invaluable and pointed out subject content of the site, historical significance of documents or passages, or possible approaches to lessons that they would never have found or understood on their own; that they had a real sense of working with people; and that the day had a stimulating professional and intellectual atmosphere.

The experts or principal investigators included both university faculty and librarians. Also involved in giving the workshop were librarians associated with the special units or collections that held the materials that were digitized, and members of the systems department-digitization unit. With this workshop staff, teachers could easily find answers to individual technical questions and about the exhibit content. The librarians and other subject experts who worked with the teachers knew the content, individual passages, and historical significance of the documents they had selected (and perhaps discovered) so well that they were able to point these out to the teachers and to suggest how they might be used and how they might meet state standards. They reviewed the draft lesson plans as the teachers worked and made suggestions, thus helping to shape the plans.

Librarians had checked with the participating teachers before the workshop to make certain that Internet access was available at their schools in some form-in the classroom, in the media center, or in a media laboratory-because it was possible in this area that such access was not practical. Access to the Internet in their schools varied, but all teachers felt they could get sufficient access for the students to work either individually or in small groups-or in a combination of these ways-to complete the lessons they planned. None of the teachers planned for substantial use of the Internet outside the class to complete the lessons.

\section{The Findings}

The workshop proved to be as valuable to the sponsors for what didn't work as for what did. These findings immediately informed lesson-plan development for the next component of the digital collections to be made available, the North Carolina History and Fiction Digital Library at East Carolina University, and they can be valuable for all work with classroom teachers in connection with digital Web sites.

The findings reinforce the need for more work with $\mathrm{K}-12$ teachers.
This is not an unworthy or impossible task. Effort spent in working with or on behalf of $\mathrm{K}-12$ users is justifiable. First, in many colleges and universities, teacher education is a substantial mission of the institution, justifying time spent in offering library service to in-service teachers (including those renewing their teaching certificates at the institution each year) or to preservice teachers. Second, making digitized sources available and usable in the schools in general also helps a public college or university to establish the presence of the institution and to meet its obligations to serve the public; it helps libraries fulfill their role as caretakers of culturalheritage materials.

Librarians regularly offer workshops or special programs for various groups of users and conduct research concerning particular groups of users and services. The educational community can be considered a significant distance-user of academic-library resources and a target of outreach efforts. Working with the K-12 community falls into these regular activities. Like all such activities, it can help librarians to improve their services.

Librarians are not without assistance in their efforts to offer workshops or undertake research on potential participants of the workshops or other services. Many states have their standards and curriculum information available online, and librarians can easily access these. Campus instructors are always available to assist librarians in areas where they feel their expertise is lacking. Campuses often offer assistance in dealing with statistics, administering surveys, or conducting research or workshops in general. Many libraries have education experts, department heads, or subject liaisons with valuable knowledge of the schools and local personnel on their own staffs. Some in-service teachers or preservice teachers are willing to work with 
digitizers either for their own interest, merit with school administrators or professors, academic credit, or a monetary stipend. Librarians can also take advantage of their normal contacts with educators, such as regular patrons, fellow committee members, $\mathrm{K}-12$ tour groups, special events such as History Day, or conferences on campus.

Continuing-education credit turned out to be, for the teachers, as important or more so than the payment they received. Teachers almost everywhere are required to earn continuing-education credits regularly in order to renew their teaching certificates. In our case, some teachers said flatly, no credit, no participation. Sometimes special credit for continuing education in technology is available, and teachers may be required to earn a certain number of credits in it. Those offering workshops or other educational programs should look into its availability.

Although participants had said they did have access to computers for their classes, it turned out that this access was not always ideal. Some teachers, for example, said they must take their classes to media rooms and that the schedules for these rooms are often quite crowded. Thus, the teacher must know a site thoroughly, be committed to its use, and plan this use well ahead of time. The chances of the site actually being used, in spite of the teachers' enthusiasm at the workshop, are greatly reduced in such a situation.

Because some teacher participants did not receive their preparatory materials far enough in advance of the workshop, they did not have sufficient experience with their assigned component when they arrived. Ideally, teachers should work enough with the site so that they know its overall content and can manipulate the site easily at the workshop. Therefore, they spent valuable workshop time in building the basic familiarity they needed to negotiate the site.
As for the various digital exhibits, ". . . the information must be accurate, organized, and accessible."13 The historical context and explanation provided with the documents should be as full as appropriate, so that the documents are easy to work with. Recent articles in education journals praise History Matters for its sections "Making Sense of Evidence" and "Learner Guides," which help students analyze and put documents in context. Organization, accessibility, and context are critical: "Thus, while providing students with primary source documents in a format (on the Web) they find easy and enjoyable encourages them to spend more time with the primary sources, unless those sources are presented in a way that also makes it possible for students to set them in their appropriate historical context, then some . . . [negative] predictions may well come true for the inexperienced student reader."14

In our case, teachers pointed out some gaps in the exhibits that would make their use more difficult in their eighth-grade classes and would mean more work for the teachers in supplying additional information or finding other online links. For example, in the Tobacco component, there was no explanation of the basic steps involved in processing tobacco or any links to it. Also, the teacher working with the founding of East Carolina University Centennial component found no explanation of the progressive era in education or other ways to easily tie the documents to the historical period. Librarians agreed that these omissions kept the exhibits from being complete and hindered their usefulness not only to the eighthgrade students and teachers but also to users of the exhibits in general.

Originally, the three lesson plans were envisioned as a unit, and that all three could be tested in the classroom. Teachers made it known before the workshop that with four hundred years of state history to cover and other curriculum requirements, this scenario was not practical. Therefore, having the lessons form a unit was not a requirement, and it was asked that only one plan be tested in the classroom in the fall.

One science teacher among the several added at the last minute to work with the John Lawson plant collection had difficulty tying the NCSCS to what he actually taught. These incidents revealed the need for more knowledge of classroom realities.

Administrative problems meant that additional participants had to be arranged for at the eleventh hour. In another last-minute addition, the head of the digitization unit asked if the not-yet-public Wright Brothers exhibit could be included in the workshop, and if several science teachers could be added to work with this and other exhibits. These additions were approved. The result was that some participants were less committed and less qualified. Librarians should try to avoid this situation. Regardless of the methods used to select teachers-and using more than one method might prove to be more effective-the commitment, qualifications, and actual teaching assignments need to be considered carefully.

What is less avoidable is that teachers suddenly receive new teaching assignments or added administrative duties. The result is that they do not have the expertise desired and require additional time and assistance to learn the resources in the digital site. Grade or subject reassignment adds a burden to even experienced teachers.

Quality control proved to be necessary where it was not anticipated. Some of the lesson plans turned in were inadequate, some were late in coming in, or did not come in at all. Some did not link to the goals and skills stated in the NCSCS. Some lesson plans did not cite the ENCDHE component used or did not tie the plans to particular primary documents. That is, some teachers did not fully understand how to incorporate an online digitized primary source into a classroom assignment. This is a problem also noted in the educational 
literature. In teaching students to become historians by using primary resources, teachers must themselves need to learn to develop a new curriculum. ${ }^{15}$

One partial solution might be to require teachers to cite or hotlink the URLs of the particular documents to their lesson plans. Another might be to provide a longer workshop in which all work can be completed and revised before the teachers leave. A 100-percent return rate was obtained for the survey about the workshop, because it was conducted then and there. Librarians might also want to involve curriculum experts from their campus or a campus nearby in their projects. ${ }^{16}$

One valuable consequence of the workshop was a new tie to LEARN NC, a statewide network for educators created and administered by the University of North Carolina at Chapel Hill's School of Education. The network assisted in the development of lesson plans for the North Carolina History and Fiction Digital Library and has mounted all lesson plans developed at workshops at Joyner Library on its site. Other states have roughly comparable programs (LEARN NC has served as a model), such as Georgia Learning Connections and the Office of Technology of the West Virginia Department of Education. ${ }^{17}$

An unexpected but most worthwhile reward of the workshop experience was a new tie to the school of education at our own institution, East Carolina University. Prior to this workshop, teacher-education classes had not come to the collection for instruction. After it was held, the first graduate class in social-studies teacher education visited the North Carolina Collection for instruction in resources available and their use.

\section{Conclusion}

Working with teachers to bring digitized primary documents into the
$\mathrm{K}-12$ classroom is desirable and worthwhile, despite its challenges.

1. Digitization of primary sources is important to the school curriculum. ${ }^{18}$

2. Both preservice and in-service teachers are not receiving sufficient training in the use of these sources or even in their existence.

3. Small workshops can be helpful to teachers. The workshops can be carefully focused on particular goals and subjects. They can be intensive and personal, build useful relationships, and benefit librarians as well as teachers.

Not only do teachers need to come and learn about the new resources and technology available, librarians need to work more closely with teachers in order to: (1) construct more useful digital sites and (2) educate teachers effectively about them and their use.

Workshops benefit both librarians and teachers in this regard.

Cherry explains what ideally might be involved in working with the $\mathrm{K}-12$ community to fulfill our roles as caretakers of cultural heritage and as public educators:

To know them better, user studies will need to be conducted, studies that will ask what curriculum and pedagogical standards need to be met? What types of constructive activities meet the needs of these standards? What types of materials do the activities require? What level of "structured access," interpretation, or curation should these materials enjoy? And how large should the underlying body of "raw data" be, which feeds the "interpreted" or "exhibit" layer of access? ${ }^{19}$

Although gaining the knowledge needed will require work for librarians, it also holds great potential for the K-12 schools, both teachers and students, as well as for the librar- ians involved in digitizing and their institutions.

\section{References and Notes}

1. Kevin Cherry, "Web-Based Heritage Materials and the K-12 Community," (Draft Ph. D. diss., Univ. of North Carolina at Chapel Hill, April 2003), 4.

2. Barbara Baruth, "Missing Pieces That Fill in the Academic Library Puzzle," American Libraries 33 (June/July 2002): 58-63. Accessed online through Library Literature and Information Science, Nov. 23, 2004. In addition to Baruth: Under the provisions of the Morrill Act of 1862, land was granted by the federal government so that at least one landgrant college was established in every state. Originally these public institutions were intended to teach agriculture and mechanical arts in addition to science and the classics, so that the industrial classes could enjoy a liberal and practical education. Through additional legislation over the years, the land-grant system has evolved into a scheme of colleges and universities managed by the states under broad federal policies and requirements.

3. Ibid.

4. Cherry, "Web-Based Heritage," 24.

5. David Trask, "Did the SansCulottes Wear Nikes?" The Impact of Electronic Media on the Understanding and Teaching of History," The History Teacher 35 (Aug. 2002): 479.

6. T. Mills Kelly, "For Better or Worse? The Marriage of the Web and Classroom," JAHC 3 (Aug. 2000): 4-5. Accessed Nov. 23, 2004, http://mcel. pacificu.edu/JAHC/JAHCIII2/ARTICLES/kelly/kelly.html.

7. John Lee, "Digital History in the History/Social-Studies Classroom," The History Teacher 35 (Aug. 2000): 510.

8. Richard Diem, "Can It Make a Difference? Technology and the Social Studies," Theory and Research in Social Education 28 (Fall 2000): 497.

9. T. Keiper, A. Harwood, and B. E. Larson, "Preservice Teachers' Perceptions of Infusing Computer Technology into SocialStudies Instruction," Theory and Research in Social Education 28 (fall 2000): 568.

10. Joseph A. Braun, "Ten Ways to Integrate Technology into Middle School Social Studies," Clearing House 72 (July/ Aug. 1999):345-51.Accessed Nov. 23,2004, 
http://search.epnet.com/direct.asp?an= 2013891\&db=afh.

11. Kelly Schrum, "Making History on the Web Matter in Your Classroom," The History Teacher 34 (May 2001): 328.

12. Cherry, "Web-Based Heritage," 23.

13. David Kobrin, "Using History Matters with a Ninth-Grade Class," The History Teacher 34 (May 2001): 340.

14. Kelly, "For Better or Worse," 6.

15. Kathleen Ferenz, "The Bay Area National Digital Library Project and the Library of Congress," in History. edu: Essays on Teaching with Technology, Dennis Trinkle and Scott Merriman, eds. (Armonk, N.Y.: M. E. Sharpe, 2001), 128.

16. The survey asked for responses to these questions:

- Please let us know one or more strengths of this workshop.

- How can we improve this workshop for the next group of teachers?

- Please write a short evaluation of your experience working with the principal investigators to examine the primary documents.

- How easy/difficult is it to integrate primary documents into your lesson planning and your Standard Course of Study?

- Please comment on how enthusiastically or how cautiously your students will approach studying primary documents in an electronic format.

- Please comment on your level of enthusiasm/apprehension about using electronic formats in the classroom.

- What strengths do you find in planning lessons for digital resources? What weaknesses?

- Please discuss your access to a computer lab, a computer screen projector, and/or classroom computers as they relate to these lessons.

- What other subjects/topics would you like to have discussed in future digital exhibits?

17. LEARN NC can be found at www. learnnc.org; Georgia Learning Connections at www.glc.k12.ga.us; and West Virginia Department of Education at http:/ / access .k12.wv.us.

18. Judith A. Lira, "Born Digital: A New View of Primary Source Materials," Colorado Libraries 26 (Winter 2000): 15.

19. Cherry, "Web-Based Heritage," 24.
Project-

Management Tools for Libraries: A Planning and Implementation Model Using Microsoft Project 2000

\section{Ying Zhang and Corinne Bishop}

This paper discusses how Microsoft Project 2000 was utilized at the University of Central Florida Libraries to manage an e-reference implementation project. As libraries today adopt more information technologies, efficiently managing projects can be challenging. The authors' experience in the implementation of QuestionPoint e-reference software in October 2003 is described. Their conclusion illustrates that project-management tools, such as Microsoft Project 2000, offer practical workflow-management techniques for libraries. This article represents the first attempt to discuss the use of Microsoft Project 2000 to manage a library project.

The University of Central Florida (UCF) is a Research II metropolitan university with an enrollment of approximately forty-two thousand students. The university's main campus is located in Orlando, Florida, with twenty-one regional campuses located throughout the central Florida area. Providing equitable research assistance to distributed-learning students at all UCF campuses is one of the top priorities of the university and one of the greatest challenges that the libraries face.

To meet the increasing demand for research assistance from distributed-learning students, the main library expanded its existing e-reference service in January 2002 by adding an online chat component. During the period of January 2002 through January 2003, the number of online chats steadily increased, and by July 2003 a decision was made to evaluate new software applications that offered enhanced features. QuestionPoint was ultimately selected because it met the overall criteria, which included integrated features for chat and e-mail, statistical tracking, and access for multiple operators. QuestionPoint also offered the advantages of participation in national and regional consortia services with other academic libraries.

\section{Why a Project- Management Tool?}

To efficiently manage the implementation of QuestionPoint and enhance communication during the project, it was decided to use Microsoft Project 2000 (MSP 2000), a project-management software tool. There are several project-management software programs on the market, and the decision to use MSP 2000 was mainly based on convenience: members of the implementation team had previously used MSP 2000 and the UCF library owned a copy.

Project-management or workflowmanagement software programs are widely used in the computer industry and information-technology sectors. As libraries today adopt additional technologies to meet the demands for information access, project-management tools offer practical methods for efficiently managing projects. Generally, these tools enable project managers to define a project's scope and manage requirements for resources, time, and costs throughout a project's lifecycle. Schachter points

Ying Zhang (yzhang@mail.ucf.edu) is Coordinator of Information Source and Associate Librarian, and Corinne Bishop (cbishop@mail.ucf.ed) is a recent MLIS graduate and Ask-A-Librarian Senior Library Technical Assistant at the University of Central Florida 
out in a recent article in Information Outlook that librarians are frequently called upon to take on the role of project managers-"We don't often call ourselves project managers, but the fact that we do so much project management as part of our regular positions is increasingly being acknowledged and promoted as a core skill set of librarianship."1

The implementation of QuestionPoint e-reference at the UCF library was a relatively small project compared to typical technology projects. However, the objectives that typify the key functions of project management were applicable. They include the ability to assess the overall requirements for the project, track tasks, allocate resources, and share information with such stakeholders as the library administration, reference department head, and Ask-A-Librarian staff. The evaluation phase prior to the selection of QuestionPoint lasted for more than five months and involved several staff members. Tasks were assigned largely with an ad-hoc approach and communication relied primarily on e-mail messages since meetings were difficult to arrange. Inevitably, some efforts were duplicated or missed, and it became clear that a more coordinated effort would be needed for the implementation phase. Consequently, to coordinate the QuestionPoint implementation phase, it was decided that a projectmanagement tool offered a practical solution.

\section{Overview of MSP 2000 Features}

The first step in building a project plan is defining the project, which involves outlining the scope or lifecycle of the project. $^{2}$ The lifecycle of UFC library's QuestionPoint implementation included three phases-Preplanning, the QuestionPoint Profile, and the Interface Customization. ${ }^{3}$ A key objective in developing the project plan was to outline each task required to complete the project. Since task information was primarily outlined in the OCLC/QuestionPoint-implementation materials, this was easy to accomplish. However, creating a project plan enabled the authors to assemble all of the task information in a core file with estimated completion dates and additional task-related information. This improved the ability to manage tasks, track deadlines, schedule staff, and share up-to-date information with stakeholders.

The QuestionPoint project plan was developed using a top-down planning method. The highest level or Summary tasks were identified, followed by a breakdown of the related subtasks. Figure 1 shows the QuestionPoint project plan in the Gantt Chart view, which is Microsoft Project's default view. This displays an outline of the project information and data fields. It includes (from left to right) task identification numbers, indicators (related information), task names, task durations, task start and finish dates, task relationships, and a list of the staff members assigned to tasks. Although the fields in the project plan look similar to those used in Microsoft Excel, MSP 2000 functions more like a database than a spreadsheet program. Data in the project fields are used to calculate task durations, resource schedules, costs, and the project's critical path, which is the series of all tasks that dictates the finish date of the project.

In addition to the Gantt Chart view, MSP 2000 provides several other options for viewing project plans. ${ }^{4}$ The Tracking-Gantt view shown in figure 2 displays the same fields as the Gantt Chart in the left side of the window. In the right side of the window, the TrackingGantt view displays task durations, assigned resources, and Summary tasks, which are plotted with bar graphs. This graphical view can be useful to quickly scan the status of tasks.
The Task-ID field contains the number assigned by MSP 2000 to individual tasks. Indicator icons, displayed in the Indicators field, represent additional task information. Check marks in the Indicators field (figure 2) represent 100-percent task completion.

MSP 2000 provides options to add other related information, such as hyperlinks, in the Indicators field. Using hyperlinks as indicators for tasks 25 and 26 enabled the authors to link directly from the project plan to chat and e-mail setup information on the QuestionPoint.org Web site. ${ }^{5}$ As shown in figure 2, placing the mouse over the hyperlink icon displays a pop-up note with additional information about the indicator. Notes can be added in the Indicators field also, which is a practical way to include follow-up information or task details.

Bolded headings in the TaskName fields are called Summary tasks and identify the major phases of the project. The indented subtasks identify the steps for completion of each phase. Information in the Duration, Start, and Finish fields was identified from fixed deadlines for specific tasks, estimates based on the QuestionPoint implementation materials, estimates from previous software-implementation projects, and the task estimates calculated by MSP 2000.

As is often the case, certain tasks have to be completed in a specific order. The Predecessor field is used to set dependency relationships and establish the sequence in which tasks should be completed. This requires that "relationship linking" be set to indicate task dependency. As shown in figure 2, tasks 7-9 and 15-19 identify task-dependency relationships assigned in the Predecessors field. A common dependency control is the finish-to-start dependency in which the finish date of the predecessor task determines the start date of the successor task. However, MSP 2000 has other dependency options such as 


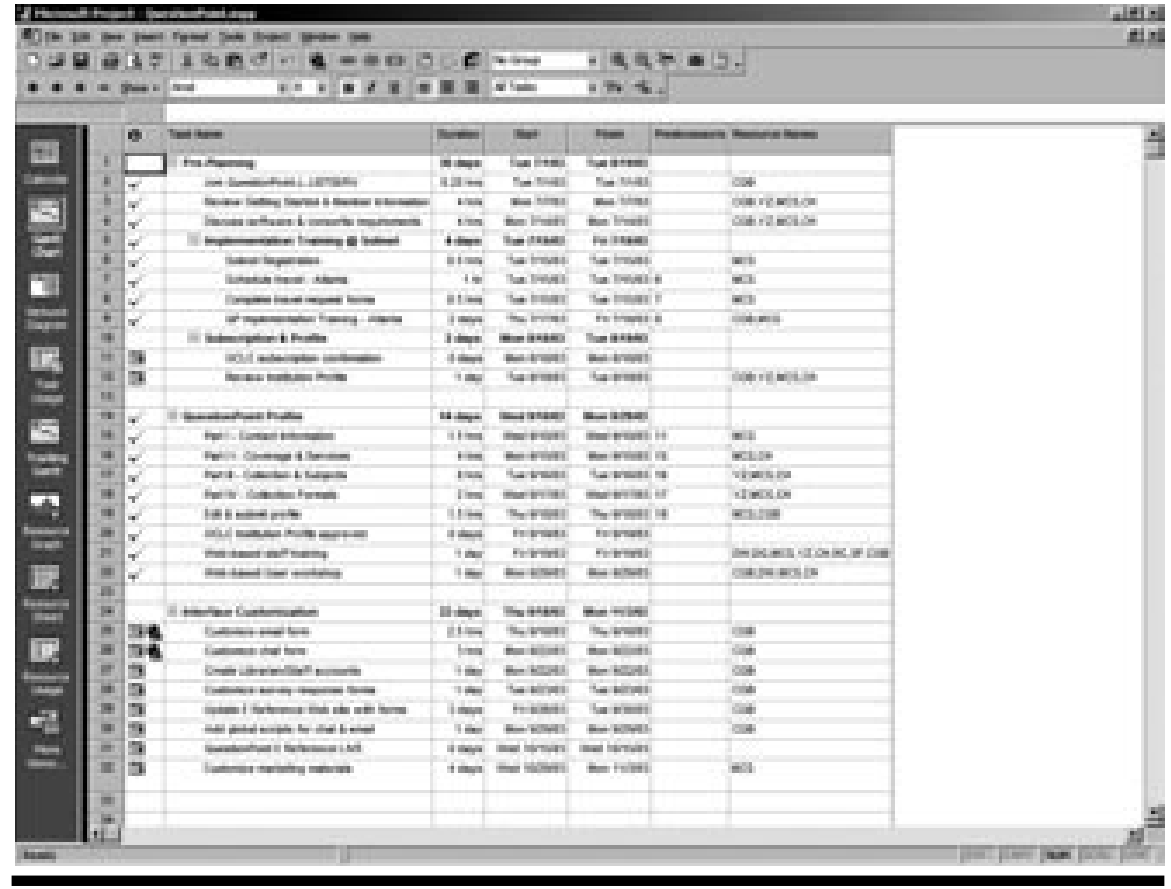

Figure 1. Gantt Chart

the start-to-start dependency, which is used for tasks that occur simultaneously when the start date of the predecessor task determines the start date of the successor task.

In the Resource-Names field, the initials of each staff member assigned to a task are displayed. Staff assignments are also displayed in the Tracking-Gantt bar graph beside the assignment durations. Resource information is recorded and linked from a separate project resource sheet. Resource Sheets are easy to set up and offer advantages for managing project assignments and calculating costs. Tracking taskassignment durations and resource allocations are an important focus of project management. MSP 2000 uses effort-driven scheduling as the default option for these calculations. The basic idea of effort-driven scheduling is that if two people (resources) are assigned to a task, the task duration is cut in half. However, this formula is not suitable for every task, which was the case in
Unlike the Gantt Chart, which shows a timescale view, the Network Diagram view shown in figure 3 displays project activities in a flowchart diagram. This view is useful to convey the relationships between tasks, rather than focusing on task durations. As is the case with other project views, it is possible to control which fields are displayed in the Network Diagram with filters.

\section{Reports}

MSP 2000 report options can be used to generate basic reports using templates or customized reports that make use of filters to select specific criteria. The report options are designed so that reports can be viewed and printed from the PrintPreview window only. This means that in order to view reports before printing, it is necessary to use the print-preview option as shown in the Task-Usage Report in figure 4.

Another printing suggestion is to always use the Print-Preview option before printing a project view such as the Tracking-Gantt chart shown. Project information displayed in the project-plan windows is usually only a small portion of the full project view that will be printed. This means that even relatively small projects can print several pages as shown in the print-preview Tracking-Gantt view in figure 5.

\section{Problems and Successes}

MSP 2000 has a moderate learning curve and is not highly intuitive. Depending on the project-management software an organization chooses and the level of experience staff possesses, considerable lead-time may be required to learn how to use such a software program. As with all other software programs, it is usually necessary to purchase a site license for multiple 


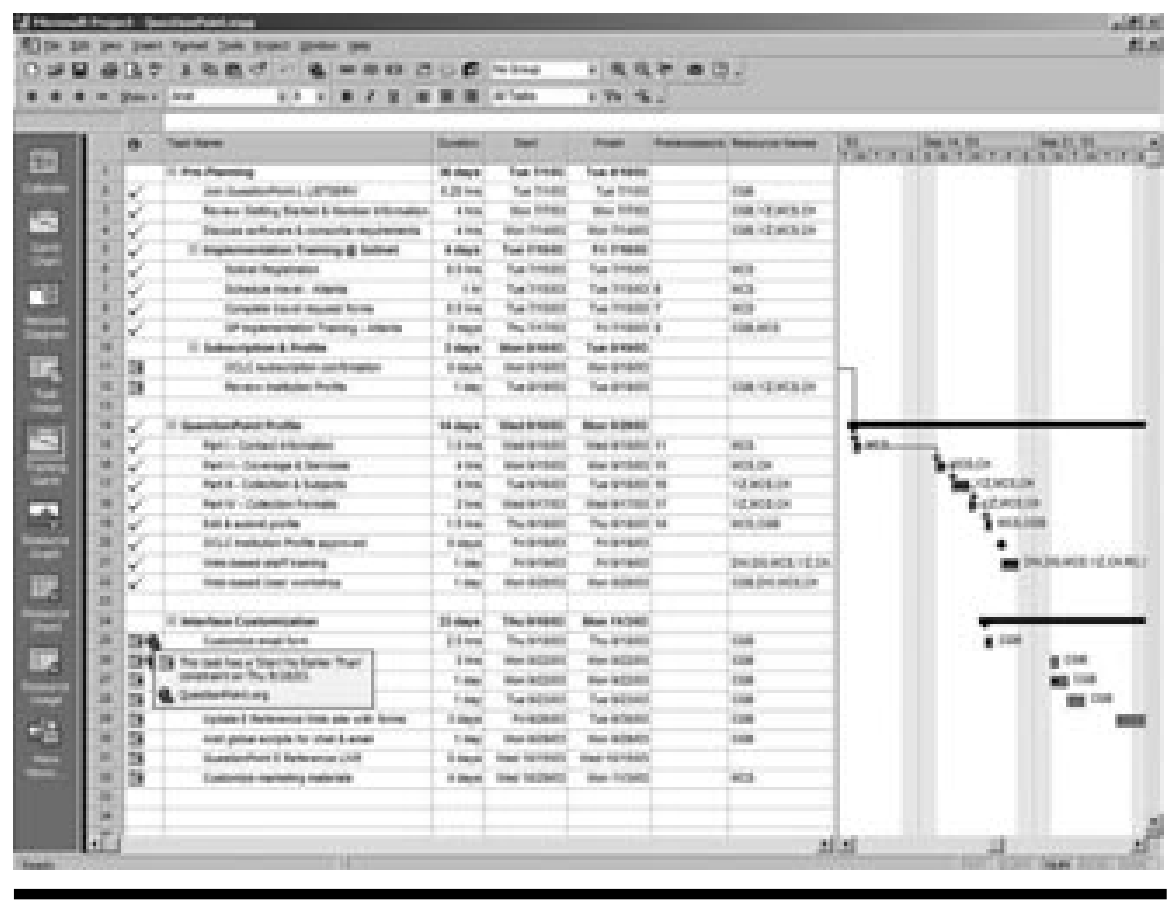

Figure 2. Tracking-Gantt Chart

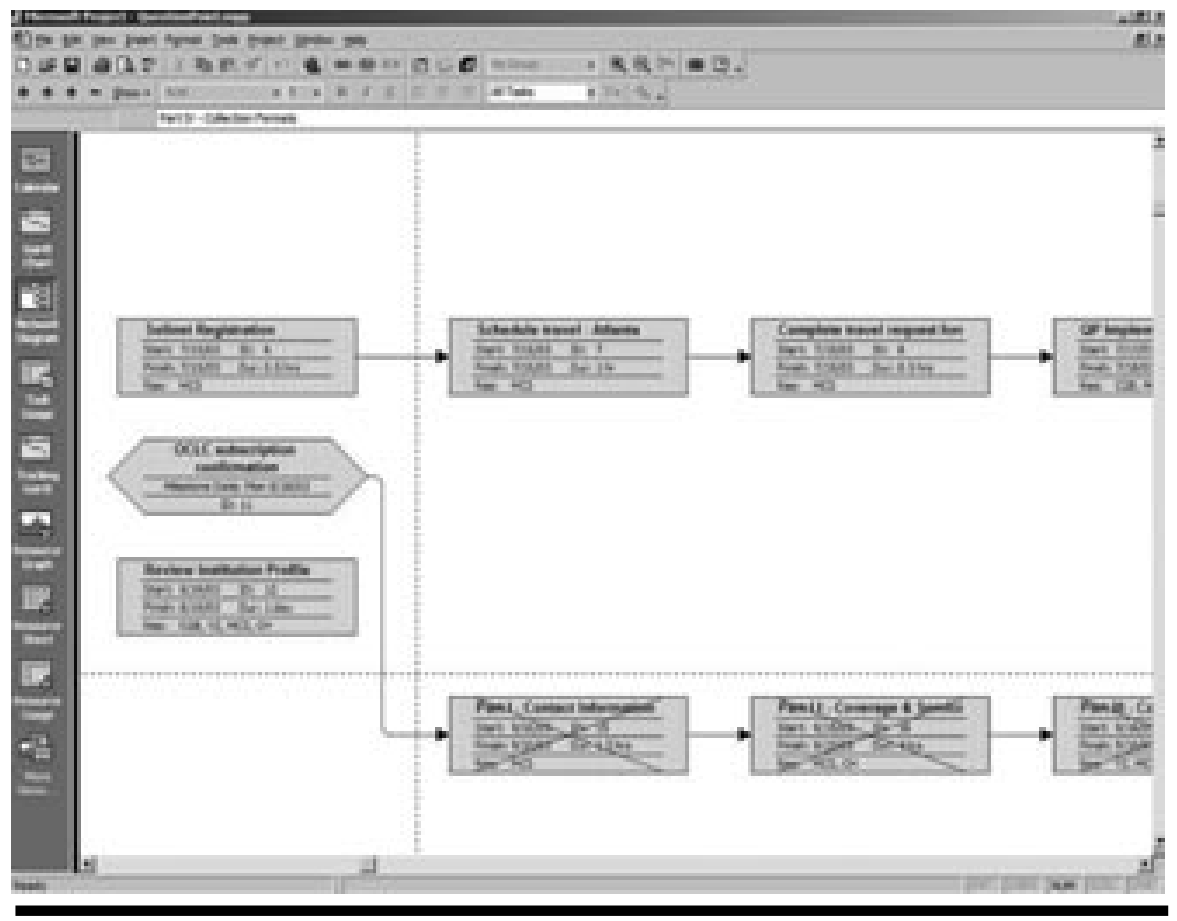

Figure 3. Network Diagram

Note: The tasks marked through in figure 3 have been completed users. Another factor to be considered is the risk of being locked-in to an expensive program that may not serve future purposes. ${ }^{6}$ Finally, there are the cost considerations of purchasing software. ${ }^{7}$ For small projects, learning a project-management program does not necessarily offer huge advantages. Instead it may be more practical and efficient to create an Excel spreadsheet to manage a small project.

For the authors, one hurdle in using MSP 2000 had to do with setting the right formula to calculate the work or task durations in relation to the number of people (resources) assigned to a task. As mentioned previously, MSP 2000 uses effort-driven scheduling as a default formula to calculate work (task durations). The formula is: Duration $x$ Units $=$ Work. The program calculates the duration of tasks contingent upon the number of units (resources) allocated to complete it. With effort-driven scheduling turned on, task durations are automatically calculated and entered into the project plan. In some instances this worked well, but in other instances this formula skewed task-completion times and caused resources to be assigned an overallocated or underallocated status. To solve this problem, it was necessary to assign some resources with effort-driven scheduling turned off, allowing the assignment of multiple resources to tasks while maintaining accurate task durations. (The effort-driven option is displayed in the tools section in the lower right pane of the Task-Entry form in figure 6.)

Although using a project plan for the QuestionPoint implementation was not required, it was believed to be beneficial. Using MSP 2000 offered options to manage tasks efficiently from a core file that served as a reliable source for up-to-date information. The project plan also provided the authors with a way to evaluate the project at each stage and allowed for adjustment in deadlines when necessary. 
The time invested in setting up the project plan provided substantial benefits when the project began. In a relatively short time, a comprehensive timeline for the project was drawn up, from which completion dates for individual tasks and the entire project could be approximated. Overall, using the project plan made it possible to manage deadlines, control actual and planned tasks, and communicate with stakeholders throughout the project. It also provided a means to evaluate the progress of the project after its completion. The authors believe the advantages of using MSP 2000 for the project outweighed the disadvantages.

\section{Conclusion}

Before deciding to use MSP 2000 or another project-management tool, it is suggested that issues such as the size of the project, experience with a project-management program, and the availability of project-management software be considered. Project-management tools offer the potential for streamlining the management of library projects and enhancing the level of planning and communication-all of which are beneficial to the success and ontime completion of projects. The authors' experience illustrates that using programs such as MSP 2000 can provide a practical approach to planning detailed projects and function as powerful workflowmanagement tools to implement library technologies.

There have been several philosophical and theoretical discussions on project management in libraries. ${ }^{8}$ In fact, it has been suggested that project management can be applied to electronic resources, reconfiguring libraries to accommodate twenty-first-century learning styles, and to integrate academic-library projects with projects in other areas of the university. ${ }^{9}$ In this paper's literature review, the authors did

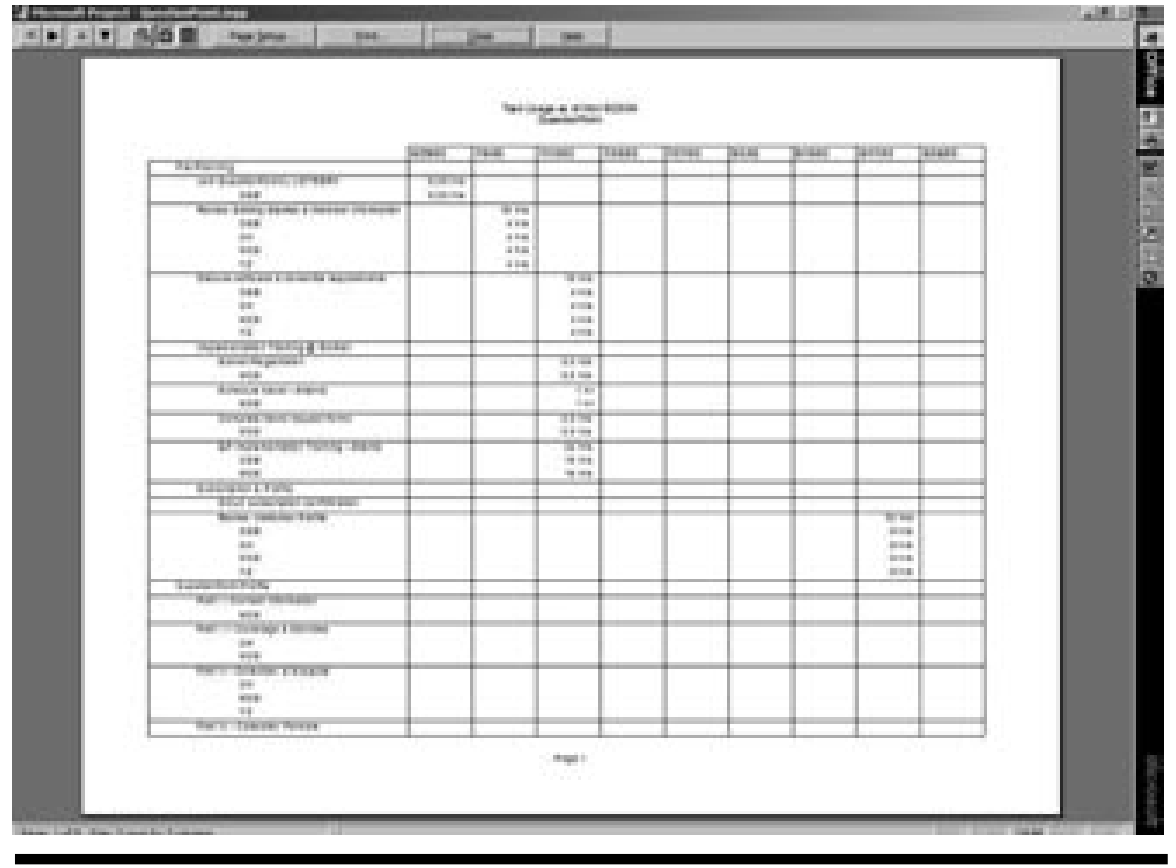

Figure 4. Task Usage Report

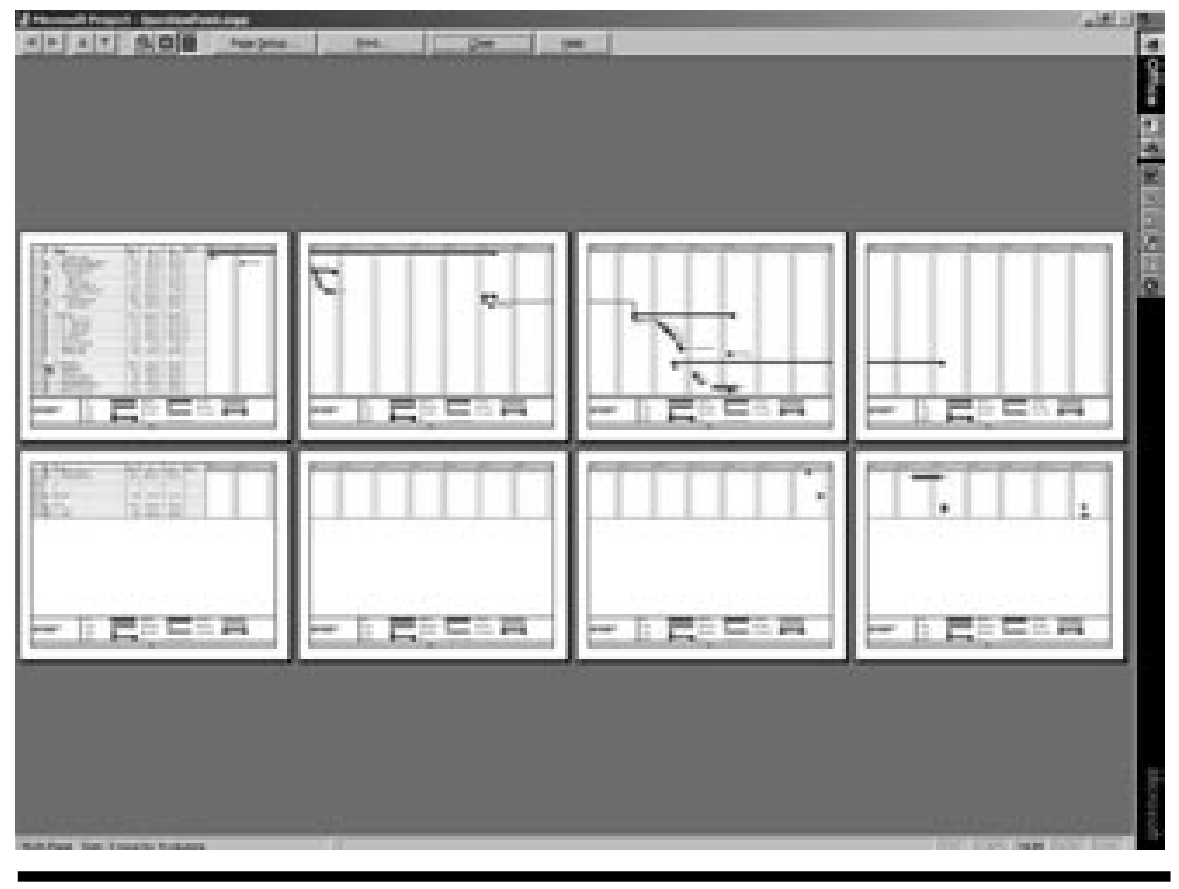

Figure 5. Tracking-Gantt Print Preview

not discover any previous articles written about the use of MSP 2000 or other project-management applications in libraries. This discussion 


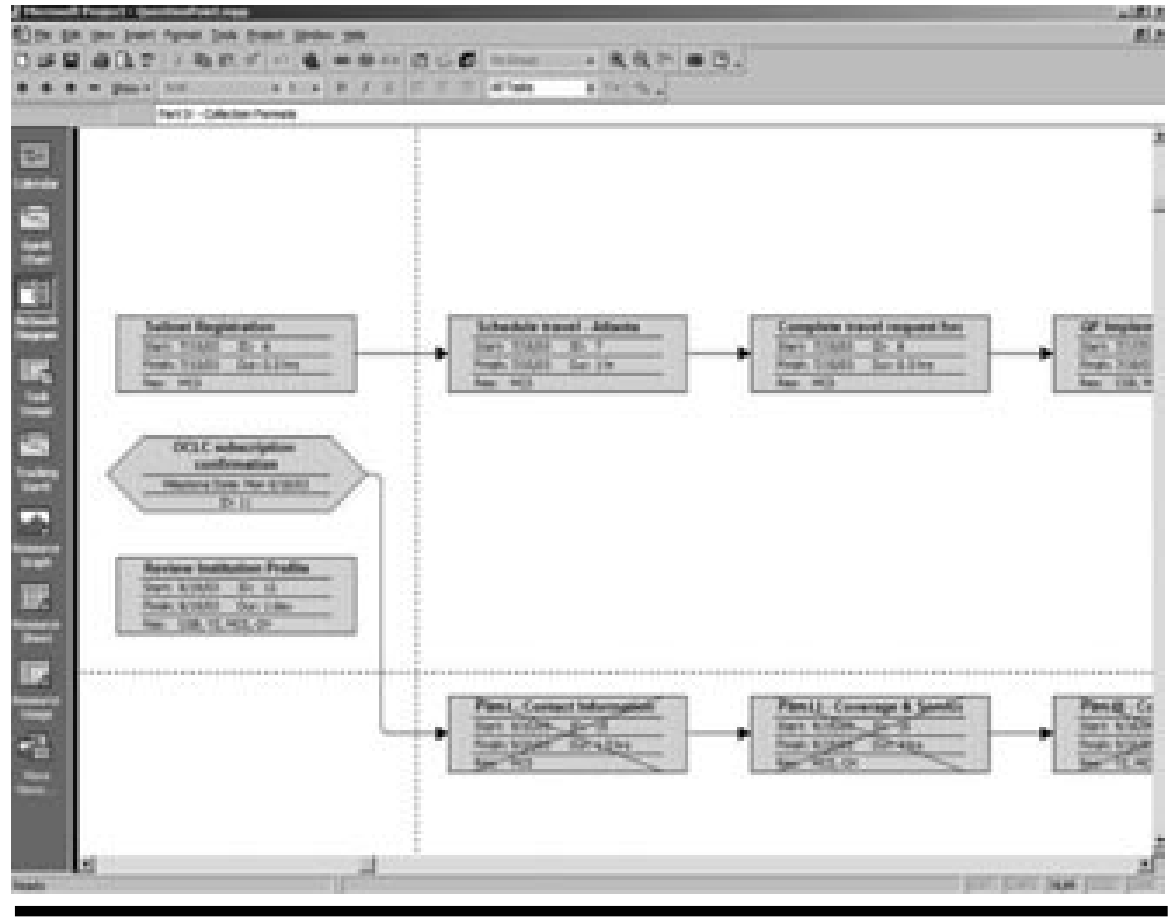

Figure 6. Task Entry

merely describes the basic features of MSP 2000, and is not intended to provide an in-depth or exhaustive example of the program. tion Outlook (Special Libraries Association) 8 , no. 2 (2004): 10-12.

2. Carl S. Chatfield and Timothy D. Johnson, Microsoft Project 2000 Step by Step (Redmond, Wash: Microsoft Press, 2000).

3. OCLC, Administrator of a QuestionPoint Full Subscriber with Standard Communications (Nov. 20, 2003). Accessed Sept. 20, 2004, www.questionpoint.org/ support/documentation/ck_ws/ig_ck_ instadmin_locglb.pdf.

4. Elaine J. Marmel, Microsoft Project 2000 Bible (Foster City, Calif.: IDG Books Worldwide, 2000).

5. OCLC, QuestionPoint Cooperative Virtual Reference (2003). Accessed Nov. 22, 2003, http:/ /questionpoint.org/support/ implementation.html.

6. George M. Marakas, System Analysis and Design: an Active Approach (Upper Saddle River, N.J.: Prentice Hall, 2001).

7. Project-Management Institute (2004). Accessed Jan. 10, 2004, www.pmi.org.

8. Edwin M. Cortez, Sanjay K. Dutta, and Edward John Kazlauskas, "What the Library and Information Professional Can Learn from the Information Technology and Project-Management Knowledge Areas," Portal: Libraries and the Academy 4, no. 1 (2004): 131-44.

9. Tracey Stanley, "Library Project Management in a Collaborative Web-based Working Environment," The New Review of Academic Librarianship 10 (2003): 70-83. Library's Technology Projects," Informa-
1. Debbie Schachter, "Managing Your

\section{References and Notes}

\section{Index to Advertisers}

Art \& Tech

EBSCO
122

cover 2
LITA

Techbooks
116,129 , covers $3-4$

141 